\title{
Calculating the dose of cisplatin that is actually utilized in hyperthermic intraperitoneal chemotherapy among ovarian cancer patients
}

Wu-yun Wang ${ }^{1,2+}$, Miao-fang Wu${ }^{1 \dagger}$, Dong-bing Wu' ${ }^{1}$ Li-juan Wang ${ }^{1}$, Hui Li ${ }^{1}$, Zhong-qiu Lin ${ }^{1 *}$ and Jing Li ${ }^{1 *}$ (D)

\begin{abstract}
Background: Hyperthermic intraperitoneal chemotherapy (HIPEC) is an important treatment for ovarian cancer. A certain portion of cisplatin exits the body via the perfusate at the end of HIPEC, so full-dose utilization cannot be achieved. Herein, we sought to explore how much cisplatin is actually utilized and its prognostic influence.

Methods: Cisplatin $\left(70 \mathrm{mg} / \mathrm{m}^{2}\right)$ was given at $43^{\circ} \mathrm{C}$ for $90 \mathrm{~min}$. The actually utilized dose (AD) of cisplatin was calculated using the following formula: $A D(m g)=$ total dose (TD) (mg)-losing dose (LD) (mg); $L D=$ volume (ml) of the perfusate $\left(V_{\text {retained }}\right)$ that was retained in the HIPEC treatment system at the end of HIPEC ${ }^{*}$ concentration of cisplatin in the perfusate $(\mathrm{mg} / \mathrm{ml})$.

Result: Sixty-two ovarian cancer patients were included. The median TD, median LD and median AD were $95 \mathrm{mg}$, $20.7 \mathrm{mg}$ and $75.8 \mathrm{mg}$, respectively. The utility rate of cisplatin (AD/TD ratio) was $79.2 \%$. On simple linear regression analysis, the TD and $V P_{\text {retained }}$ were found to significantly predict the AD. Based on these two factors, multiple linear regression analysis was conducted, and a significant regression equation was formulated $[F(2,59)=71.419, P<$ $0.0001]$ : predicted $\mathrm{AD}(\mathrm{mg})=30.079+0.667 \mathrm{TD}(\mathrm{mg})-0.010 \mathrm{VP}_{\text {retained }}(\mathrm{ml})$ (adjusted $\left.R^{2}=0.698\right)$. In Cox regression analysis, AD was not noted to be associated with progression free survival or overall survival.
\end{abstract}

Conclusion: For ovarian cancer patients who receive cisplatin for HIPEC at $43{ }^{\circ} \mathrm{C}$, the AD of cisplatin can be predicted using a regression equation and it has no prognostic impact.

Keywords: Ovarian cancer, Cisplatin, Hyperthermic intraperitoneal chemotherapy, Dose

\section{Introduction}

Ovarian cancer is the deadliest gynecologic cancer and is usually diagnosed after the cancer has spread beyond the ovary [1]. Primary debulking surgery (PDS) combined with chemotherapy has been the first-line treatment for ovarian cancer patients.

\footnotetext{
*Correspondence: zhongqiu_lin@163.com; lijing228@mail.sysu.edu.cn 'Wu-yun Wang and Miao-fang Wu contributed equally to this work. ${ }^{1}$ Department of Gynecologic Oncology, Sun Yat-sen Memorial Hospital, Sun Yat-sen University, Guangzhou 510120, People's Republic of China Full list of author information is available at the end of the article
}

However, even among patients without evidence of disease following treatment, $70 \%$ experience recurrence within the subsequent 3 years, and almost $80 \%$ succumb to their disease [2].

Because of a clear tendency to develop peritoneal metastasis, attempts to improve outcomes for this patient population have prompted the investigation of intraperitoneal chemotherapy (IPC), and its effect has been validated [3]. IPC can also be delivered under hyperthermic conditions, which is termed hyperthermic intraperitoneal chemotherapy (HIPEC). An increasing number of

C C The Author(s). 2021 Open Access This article is licensed under a Creative Commons Attribution 4.0 International License, which permits use, sharing, adaptation, distribution and reproduction in any medium or format, as long as you give appropriate credit to the original author(s) and the source, provide a link to the Creative Commons licence, and indicate if changes were made. The images or other third party material in this article are included in the article's Creative Commons licence, unless indicated otherwise in a credit line to the material. If material is not included in the article's Creative Commons licence and your intended use is not permitted by statutory regulation or exceeds the permitted use, you will need to obtain permission directly from the copyright holder. To view a copy of this licence, visit http://creativecommons.org/licenses/by/4.0/. The Creative Commons Public Domain Dedication waiver (http://creativecommons.org/publicdomain/zero/1.0/) applies to the data made available in this article, unless otherwise stated in a credit line to the data. 
studies have shown a survival benefit associated with HIPEC among ovarian cancer patients [4-8]. Based on this evidence, HIPEC has been recommended in the National Comprehensive Cancer Network (NCCN) guidelines for patients receiving interval debulking surgery (IDS) [9]. In the China Anti-Cancer Association (CACA) guidelines, HIPEC is recommended as an adjuvant treatment for gynecologic cancer patients with peritoneal carcinomatosis; currently, it has been a publicly approved therapy in China and its costs are covered by insurance plans [10].

Owing to a favorable peritoneal plasma gradient, cisplatin is the preferred agent for IPC [11]. The addition of hyperthermia to intraperitoneal cisplatin can result in synergistic effects, thereby enhancing cytotoxicity [12]. Therefore, cisplatin is also the most commonly used drug in HIPEC [13]. A noteworthy observation in clinical practice is that a certain portion of cisplatin exits the body via the perfusate at the end of treatment, so full cisplatin uptake cannot be achieved. Previous investigations have explored the pharmacokinetic features of cisplatin in HIPEC [14-16]. However, no investigator could provide a clear-cut answer to the following critical question: how much cisplatin is actually utilized by a patient during HIPEC? Accordingly, it is unclear whether the amount of cisplatin depletion adversely affects therapeutic effect. We herein conducted a study to predict the actual uptake dose of cisplatin based on clinical variables that are easy to obtain and investigate its prognostic effect. From a clinical perspective, we believe that our findings are conducive to optimizing the dose planning and schedule of cisplatin in HIPEC.

\section{Materials and methods}

After Institutional Review Board approval was obtained (Approval No. SYSEC-KY-KS-2020-046), a retrospective chart review was conducted. Ovarian cancer patients who received cisplatin for HIPEC between 2016 and 2018 were identified. Patients who were considered for HIPEC underwent detailed counseling with regard to the potential risks and benefits within the context of previously published clinical trials and guidelines. All patients provided signed informed consent. Data from patients who received intravenous platinum within 2 weeks before HIPEC and patients who did not undergo the complete HIPE $C$ procedure were excluded.

Surgical complexity of the debulking surgery was based on a complexity score which was calculated using a published scoring system [17]. At the end of cytoreduction, four tubes were placed (two in the bilateral subdiaphragmatic space for use as inlet tubes and two in the pelvic cavity for use as an outlet tubes) before closing the incision, which were used to administrate HIPEC. HIPEC was given following surgery using a close technique. A high-precision hyperthermic intraperitoneal perfusion treatment system with a precision of $\pm 0.10^{\circ} \mathrm{C}$ for temperature control and \pm $5 \%$ for flow control (approved by the State Food Drug Administration of China, approval no. 2009-3,260,924) was utilized. Cisplatin was given at a dose of $70 \mathrm{mg}$ per square meter and was added to $3000-5000 \mathrm{ml}$ of saline solution. The perfusate was heated and circulated at a flow rate of $300-500 \mathrm{ml} / \mathrm{min}$. The perfusion velocity was adjusted to ensure that the entire abdomen was exposed to the perfusate (the initial velocity was $300 \mathrm{ml} / \mathrm{min}$ and increased gradually until the patient felt floated or until a flow rate of 500 $\mathrm{ml} / \mathrm{min}$ was achieved). An intraabdominal temperature of $43^{\circ} \mathrm{C}$ was maintained and measured by the treatment system using temperature monitoring probes in the infusion and outflow catheters. The HIPEC procedure took $90 \mathrm{~min}$ in total, consisting of a 30 min preheating period and a 60 min perfusion period. All patients received continuous intravenous fluids to assure adequate hydration. During the treatment, vital signs and urine output were monitored continually. After HIPEC treatment, the perfusate retained in the treatment system and in the tubes was collected after removing the tubes, and then the volume was measured. Thereafter, a portion of the perfusate was stored at $-80^{\circ} \mathrm{C}$ and analyzed within 3 weeks. Perfusate collecting and volume assessment have been integrated into routine clinical care in our institution since 2015. Cisplatin concentrations in the perfusate were measured by inductively coupled plasma mass spectrometry (ICP-MS; PerkinElmer, America). The National Cancer Institute Common Terminology Criteria for Adverse Events (NCI-CTCAE) Version 4.0 was used to grade HIPEC-related adverse events (AEs) that presented within 3 weeks of HIPEC.

The Kolmogorov-Smirnov test was used to determine the distribution of continuous variables. Student's $t$ test was used to compare normally distributed continuous variables, whereas the Mann-Whitney $U$ test was used to compare nonnormally distributed variables. The following equation was applied to calculate the quantity of cisplatin uptake during HIPEC:

$$
\begin{aligned}
& \text { Actually utilized dose }(\mathrm{AD})(\mathrm{mg}) \\
& \quad=\text { total dose }(\mathrm{TD})(\mathrm{mg})-\text { losing dose }(\mathrm{LD})(\mathrm{mg}) \\
& \mathrm{TD}=70 \mathrm{mg} / \mathrm{m}^{2} * \text { body surface area }\left(\mathrm{m}^{2}\right)
\end{aligned}
$$

(the resulting TD was rounded to the closest integer)

$$
L \mathrm{D}=\text { volume (m) of the perfisaste }
$$

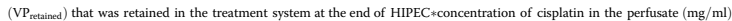

To explore associations between the $\mathrm{AD}$ and potential clinical variables, linear regression analysis was conducted. These variables included patient age, body mass index (BMI), TD, $\mathrm{VP}_{\text {retained }}$ and serum levels of creatinine and albumin prior to HIPEC. Assumptions that 
underpin linear regression were confirmed as described previously. The final regression equation was established using a multiple linear regression model with the enter method. Variables with $P$ values $<0.05$ in the simple linear regression analysis were entered into the multiple linear regression analysis. Cox proportional hazards regression model was used to explore the prognostic influence of AD. Statistical tests were two-sided, and a $P$ value $<0.05$ was considered statistically significant. All data analyses were performed with SPSS 20.0 for Windows (SPSS, Inc., Chicago, IL).

\section{Results}

A total of 62 patients were included in the final analysis. Table 1 summarizes the patient demographics and clinical characteristics. Because of massive ascites and pleural effusion, six patients had restricted activity (9.7\%). Before HIPEC, abnormal serum creatinine levels were noted in one patient (1.6\%) who had an elevated serum creatinine level $(137 \mu \mathrm{mol} / \mathrm{l})$ since diagnosis. This patient had no complaints and denied a history of kidney disease. Repeated creatinine tests and further kidney function evaluations were performed, but no evidence of acute or chronic kidney injury was identified. Then, the mean serum creatinine value $(159 \mu \mathrm{mol} / \mathrm{l})$ was used for the analysis. Of our cohort, 44 patients $(71.0 \%)$ received HIPEC following PDS, while 18 patients (29.0\%) received HIPEC following IDS.

Table 2 shows variables that were related to the cisplatin dose. The median TD and LD values were $95 \mathrm{mg}$ (range: $85-120 \mathrm{mg}$ ) and $20.7 \mathrm{mg}$ (range: $9.6-37.8 \mathrm{mg}$ ), respectively. Based on the formulation mentioned above, the median calculated $\mathrm{AD}$ value was $75.8 \mathrm{mg}$ (range: 48.3-92.4 $\mathrm{mg}$ ). The $\mathrm{AD} / \mathrm{TD}$ ratio refers to the utility rate of cisplatin, and the median percentage was $79.2 \%$ (range: 62.2-90.4\%).

The results of the linear regression analysis are summarized in Table 3. The TD and $\mathrm{VP}_{\text {retained }}$ had a linear relationship with the $\mathrm{AD}$ (Fig. 1a and b) and were able to significantly predict the $\mathrm{AD}$ on simple linear regression analysis. Based on these two factors, multiple linear regression analysis was conducted, and a significant regression equation was formulated $[\mathrm{F}(2,59)=71.419$, $P<0.0001]$, with an $R^{2}$ of 0.708 . The formula was as follows: predicted $\mathrm{AD}(\mathrm{mg})=30.079+0.667 \mathrm{TD}(\mathrm{mg})-$ $0.010 \mathrm{VP}_{\text {retained }}(\mathrm{ml})$. Therefore, when maintaining all other variables constant, the AD increased $0.667 \mathrm{mg}$ for each milligram increase in the TD, while the $\mathrm{AD}$ decreased $0.010 \mathrm{mg}$ for each milliliter increase in the $\mathrm{VP}_{\text {re- }}$ tained. Both the $\mathrm{TD}$ and $\mathrm{VP}_{\text {retained }}$ were significant predictors for the $\mathrm{AD}$. The TD and $\mathrm{VP}_{\text {retained }}$ accounted for $69.8 \%$ (adjusted $R^{2}=0.698$ ) of the explained variability in the AD. Figure 1c illustrates scatter plots of the actual vs predicted $\mathrm{AD}$ values.
Table 1 Demographic and clinical characteristics of patients

\begin{tabular}{|c|c|}
\hline Characteristic & \\
\hline Age (years), median (range) & $51(18,76)$ \\
\hline BMI $\left(\mathrm{kg} / \mathrm{m}^{2}\right)$, median (range) & $22.1(15.8,34.8)$ \\
\hline Body surface area $\left(\mathrm{m}^{2}\right)$, median (range) & $1.42(1.21,1.71)$ \\
\hline \multicolumn{2}{|l|}{ ECOG performance status (\%) } \\
\hline Normal activity & $56(90.3)$ \\
\hline Restricted activity & $6(9.7)$ \\
\hline \multicolumn{2}{|l|}{ Histology (\%) } \\
\hline High grade serous adenocarcinoma & $46(74.2)$ \\
\hline Mucinous adenocarcinoma & $3(4.8)$ \\
\hline High grade endometrioid adenocarcinoma & $3(4.8)$ \\
\hline Clear cell carcinoma & $5(8.1)$ \\
\hline Malignant mixed mullerian tumor & $5(8.1)$ \\
\hline \multicolumn{2}{|l|}{ FIGO stage (\%) } \\
\hline IIIC & $43(69.4)$ \\
\hline IV & $19(30.7)$ \\
\hline \multicolumn{2}{|l|}{ Surgical treatment (\%) } \\
\hline Primary debulking surgery & $44(71.0)$ \\
\hline Interval debulking surgery & $18(29.0)$ \\
\hline \multicolumn{2}{|l|}{ Gross residual disease (\%) } \\
\hline Yes & $43(69.4)$ \\
\hline No & $19(30.7)$ \\
\hline \multicolumn{2}{|l|}{ Surgical complexity (\%) } \\
\hline Low & $5(8.1)$ \\
\hline Moderate & $40(64.5)$ \\
\hline High & $17(27.4)$ \\
\hline \multicolumn{2}{|l|}{ ICU stay (\%) } \\
\hline Yes & $2(3.2)$ \\
\hline No & $60(96.8)$ \\
\hline \multicolumn{2}{|l|}{ Serum creatinine (umol/L), median (range) } \\
\hline Prior to HIPEC & $63.5(49,159)$ \\
\hline Following HIPEC & $62.0(48,149)$ \\
\hline \multicolumn{2}{|l|}{ Serum albumin (g/l), median (range) } \\
\hline Prior to HIPEC & $25(15,36)$ \\
\hline Following HIPEC & $22(15,30)$ \\
\hline
\end{tabular}

BMI Body mass index, ECOG Eastern cooperative oncology group, HIPEC

Hyperthermic intraperitoneal chemotherapy, ICU Intensive care unit

HIPEC-related AEs are summarized in supplementary Table 1. Following HIPEC, the most common AE was abdominal pain/distention, which was noted in ten patients (16.1\%). Four patients (6.5\%) reported AEs of grade 3, including 2 cases of neutropenia, one case of abdominal pain, and one case of vomiting. No patient developed AEs of grade 4.

Within a median follow-up time of 23 months (range: 9-35 months), recurrence was noted in 35 patients 
Table 2 Hyperthermic intraperitoneal chemotherapy related parameters

\begin{tabular}{ll}
\hline Parameter & \\
\hline TD $(\mathrm{mg})$, median (range) & $95(85,120)$ \\
Perfusate at the end of HIPEC & $1835(1050,2670)$ \\
$\quad$ Volume $(\mathrm{ml})$, median (range) & $11.3(6.6,19.4)$ \\
Concentration of cisplatin $(\mu \mathrm{g} / \mathrm{ml})$, median (range) & $20.7(9.6,37.8)$ \\
LD (mg), median (range) & $75.8(48.3,92.4)$ \\
AD (mg), median (range) & $79.2(62.2,90.4)$ \\
Utility rate of cisplatin ${ }^{a}(\%)$, median (range)
\end{tabular}

$A D$ Actually utilized dose, $L D$ Losing dose, HIPEC Hyperthermic intraperitoneal chemotherapy, TD Total dose;

atility rate of cisplatin = actually used dose of cisplatin $(\mathrm{mg}) /$ total dose of cisplatin $(\mathrm{mg})$

(56.4\%), and the median recurrence-free survival (PFS) time was 16 months (range: 4-29 months). Ten patients (16.1\%) died of disease, and the median overall survival (OS) time was not reached. In Cox regression analysis, we did not find that AD was associated with PFS [hazard ratio $(\mathrm{HR})=1.02$, 95\% confidence interval $(\mathrm{CI})$ : 0.98 1.06; $P=0.428]$ or $\mathrm{OS}(\mathrm{HR}=1.01,95 \% \mathrm{CI}: 0.95-1.07$; $P=0.813)$.

\section{Discussion}

HIPEC has evolved over three decades and cisplatin is among the first-line drugs. However, there is no clearly defined standardization of regimen for cisplatin in the hyperthermic setting, and the reported dose in previous studies varies significantly, from $15 \mathrm{mg} / \mathrm{m}^{2}$ to $250 \mathrm{mg} / \mathrm{m}^{2}$ [13, 18, 19]. The most accepted cisplatin based HIPEC regimens in literature are the "Sugarbaker Regimen" [add cisplatin $\left(50 \mathrm{mg} / \mathrm{m}^{2}\right)+$ doxorubicin $\left(15 \mathrm{mg} / \mathrm{m}^{2}\right)$ to 2 L $1.5 \%$ dextrose peritoneal dialysis solution; treatment duration: $90 \mathrm{~min}]$ [20] and the "National Cancer Institute Milan Regimen" [15.25 mg/L of doxorubicin and 43 $\mathrm{mg} / \mathrm{L}$ of cisplatin for 90-min HIPEC treatment; chemotherapy solution 4-6 L based on capacity of the peritoneal space] [13, 21]. Despite of this, neither of them has been recommended in current guidelines or validated in gynecologic cancer patients. Most of the side effects associated with hyperthermic cisplatin are dose dependent [22], so the lack of a standard dose regimen represents a notable challenge for the safe application of HIPEC. During HIPEC, the TD of cisplatin can be divided into two portions: one portion (AD) is directly absorbed or retained in the peritoneal cavity, while the other portion (LD) is retained in the perfusate and exits the body at the end of treatment. The variable $\mathrm{AD}$ is critical since it enables physicians to know the uptake quantity of cisplatin and thus can be used to tailor dose regimens. In the present study, we found that the $\mathrm{AD}$ is significantly correlated with the TD and $\mathrm{VP}_{\text {retained }}$. Based on these two factors, an equation was established with an adjusted $R^{2}=0.698$, which suggested a moderate ability to predict the AD. In addition, we did not find that $\mathrm{AD}$ had prognostic impact.

The pharmacokinetics of cisplatin under hyperthermic conditions have been investigated previously [14-16]. Cashin's study included ten patients who received HIPE $\mathrm{C}$ for peritoneal surface malignancies [14]. A combination of cisplatin $\left(50 \mathrm{mg} / \mathrm{m}^{2}\right)$ and doxorubicin $(15 \mathrm{mg} /$ $\mathrm{m}^{2}$ ) was added to the perfusate, which was administered at $41.1-43^{\circ} \mathrm{C}$ for a duration of $90 \mathrm{~min}$. The reported mean half-life $(\mathrm{t} 1 / 2)$ of perfusate cisplatin was $18.4 \mathrm{~min}$. Accordingly, the authors concluded that after $75 \mathrm{~min}$, there is little active cisplatin left in the perfusate. In another study by Ansaloni et al., 13 ovarian cancer patients received HIPEC, and a combination of cisplatin (100 $\left.\mathrm{mg} / \mathrm{m}^{2}\right)$ and paclitaxel $\left(175 \mathrm{mg} / \mathrm{m}^{2}\right)$ was given at $41-$ $43^{\circ} \mathrm{C}$ [15]. Similarly, the authors reported that both drugs could be rapidly taken up from the perfusate by peritoneal tissue and the absorption of cisplatin could not be influenced by lowering the time of perfusion to $60 \mathrm{~min}$. The present study is retrospective, so it is impossible for us to get patients' blood sample and carry out pharmacokinetic assessment. Given the importance of the amount of cisplatin actually utilized in the living body, we calculated the utility rate of cisplatin using $\mathrm{AD} / \mathrm{TD}$ ratio, which could be considered an indirect pharmacokinetic parameter. The median cisplatin utility rate in our cohort was $79.2 \%$ (range: $62.2-90.4 \%$ );

Table 3 Linear regression model results for actually utilized dose of cisplatin

\begin{tabular}{|c|c|c|c|c|c|c|}
\hline & $\beta$ & $95 \% \mathrm{Cl}$ for $\beta$ & $P$ value & $\beta$ & $95 \% \mathrm{Cl}$ for $\beta$ & $P$ value \\
\hline Age (years) & -0.012 & $-0.169,0.146$ & 0.881 & - & - & - \\
\hline BMI $\left(\mathrm{kg} / \mathrm{m}^{2}\right)$ & -0.117 & $-0.705,0.472$ & 0.693 & - & - & - \\
\hline Serum creatinine prior to HIPEC (umol/l) & 0.013 & $-0.103,0.129$ & 0.822 & - & - & - \\
\hline Serum albumin (g/l) prior to HIPEC & 0.078 & $-0.308,0.464$ & 0.689 & - & - & - \\
\hline $\mathrm{TD}(\mathrm{mg})$ & 0.777 & $0.554,1.000$ & $<0.001$ & 0.667 & $0.500,0.833$ & $<0.001$ \\
\hline$V_{\text {Pretained }}(\mathrm{ml})$ & -0.012 & $-0.016,-0.008$ & $<0.001$ & 0.010 & $-0.013,-0.007$ & $<0.001$ \\
\hline
\end{tabular}

BMI Body mass index, HIPEC Hyperthermic intraperitoneal chemotherapy, TD Total dose, $V_{\text {Pretained }}$ Volume $(\mathrm{ml})$ of the perfusate that was retained in the treatment system at the end of hyperthermic intraperitoneal chemotherapy; 


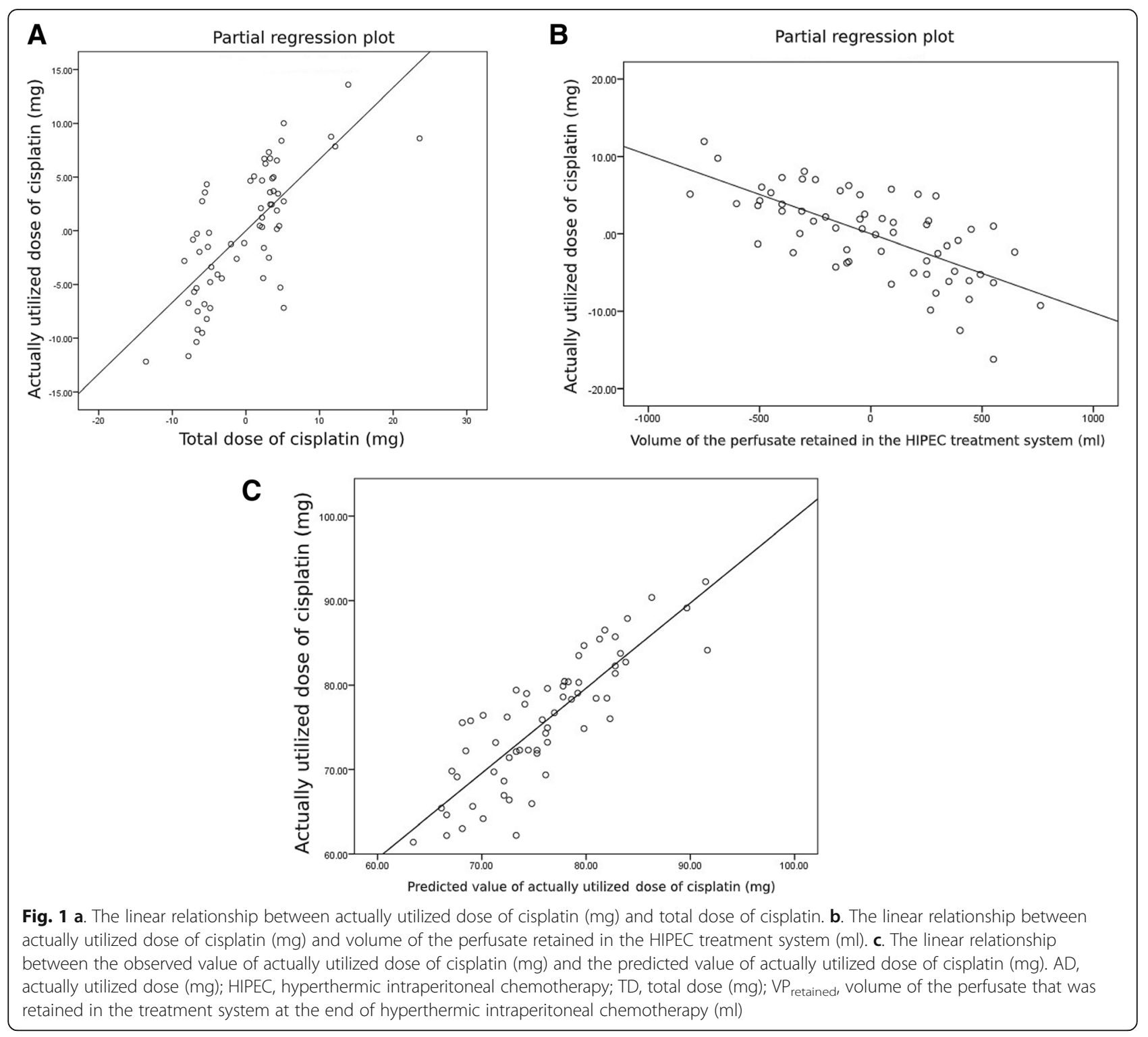

therefore, approximately $80 \%$ of cisplatin was utilized after $60 \mathrm{~min}$ of HIPEC. This result indicates efficient uptake of cisplatin during HIPEC, which is consistent with previous reports $[14,15]$. Loss of cisplatin during HIPEC is inevitable. Given our findings and current evidence, the necessity of minimizing the loss by methods such as flushing the device at the end of HIPEC is worth investigation in future studies.

In the NCCN ovarian cancer guidelines, the recommended dose for hyperthermic cisplatin is $100 \mathrm{mg} / \mathrm{m}^{2}$ [9]. This recommendation is based on the phase III OVHIPEC trial [4], where 245 patients were randomized to receive IDS either with or without HIPEC. The authors reported that the addition of HIPEC did not increase the risk of AEs. However, the administration of cisplatin in this trial was according to the following schedule: $50 \%$ of the dose at start, $25 \%$ at $30 \mathrm{~min}$ and $25 \%$ at $60 \mathrm{~min}$. In this way, the maximum dose in the abdomen was lower than $100 \mathrm{mg} / \mathrm{m}^{2}$. An additional concern is that information on the influence of HIPEC on renal function was not detailed. Therefore, it remains unknown whether a dose of $100 \mathrm{mg} / \mathrm{m}^{2}$ of cisplatin is safe for HIPEC. In the present study, all patients received a dose of $70 \mathrm{mg} / \mathrm{m}^{2}$ cisplatin. The rationality of this dose regimen has been validated in Gouy's study [23]. In the phase I dose escalation trial, four dose levels were planned for cisplatin: $50,60,70$, and $80 \mathrm{mg} / \mathrm{m}^{2}$. The observed grade 4 dose-limiting toxicity was renal insufficiency, which did not occur until cisplatin was administered at dose level $4\left(80 \mathrm{mg} / \mathrm{m}^{2}\right)$. Because several patients developed prolonged renal function impairment, the authors recommended a $70 \mathrm{mg} / \mathrm{m}^{2}$ dose of cisplatin 
for HIPEC. In the current cohort, no patients developed kidney dysfunction following HIPEC, which is in line with our previous findings and confirms Gouy's conclusion [23].

HIPEC-related kidney injury has been a clinical concern. The reported incidence of major renal toxicity ranges from 1.3 to 5.7\% [24-26]. Among previous studies regarding this issue, Cata's study, which retrospectively reviewed 475 patients, has the largest sample size examined to date [27]. The authors reported that acute kidney injury (AKI) following HIPEC was independently associated with patient age, body mass index, the use of cisplatin or oxaliplatin as the agent, the preoperative administration of pregabalin and estimated blood loss [27]. In addition, the risk of kidney dysfunction is also characterized by ethnical differences [28]. For Chinese ovarian cancer patients, Sin et al. identified predictors for AKI following HIPEC that included age, baseline levels of creatinine, the estimated glomerular filtration rate and albumin, the number of cycles of preoperative carboplatin, the time interval between NACT and debulking surgery, and the volume of blood transfusions [29]. Of note, Sin et al. reported that $9.4 \%$ of their patients developed NCI-CTCAE grade 3 and 4 renal impairment, and $5.7 \%$ of their patients needed renal replacement therapy [29]. The incidence reported in this study is much higher than that reported in other studies [24-26], and a possible explanation is that many patients received cycles of platinum-based chemotherapy before HIPEC, and a high dose of cisplatin $\left(90 \mathrm{mg} / \mathrm{m}^{2}\right)$ was prescribed in HIPEC. Although an even higher dose of cisplatin $\left(100 \mathrm{mg} / \mathrm{m}^{2}\right)$ was used in OVHIPEC trial, some aspects of the trial are questionable, which has been discussed above. Besides, all patients in this trial received sodium thiosulphate and adequate hydration. Appropriate use of these measures can effectively prevent nephrotoxicity which could also provide additional explanation for why such high dose of hyperthermic cisplatin did not result in an increased incidence of kidney injury [30]. Collectively, current evidence suggests that HIPEC-related nephrotoxicity is complex and can be affected by many factors. The selection of patients based on risk stratification, optimized cisplatin dose regimens and appropriate protective measures can help reduce the risk of HIPEC-related nephrotoxicity.

The treatment temperature in our study was $43 \pm$ $0.01{ }^{\circ} \mathrm{C}$, which is in accordance with the CACA guidelines [10]. This recommendation is based on the evidence that the synergistic effect of hyperthermia and cisplatin can be dramatically increased at $42^{\circ} \mathrm{C}$ [10]. Data from clinical research also confirmed the safety and effectiveness of HIPEC at $43^{\circ} \mathrm{C}$ [31-34]. In general, the properties of biological tissues, the toxicity of drugs and their mutual influences change under hyperthermic conditions; some of the changes are temperature dependent [35]. Therefore, it is necessary to explore drug uptake in the hyperthermic setting at a given temperature. In addition, other parameters, including flow rate during HIPEC and perfusate dwelling time, have potential impact on cisplatin uptake. However, these data were not available in the present study; their influence is worthy of further studies.

The present study provides the first tool that can be used to calculate the AD of cisplatin during HIPEC, which makes it possible to further explore and determine whether a supplementation on cisplatin is necessary in the clinical setting. Of note, $\mathrm{AD}$ can be influenced by many factors. However, since the design of present study is retrospective, the omission of potential factors is inevitable, which certainly adversely affects the accuracy of the predictive equation. In addition, the adjusted $R^{2}$ value of the predictive equation was 0.698 indicating that predictive performance has not yet reached a satisfying level. Given these limitations, we must acknowledge that the prediction formula still needs to be refined and more trials are needed to validate its performance. In addition, HIPEC is recommended as an adjuvant therapy following cytoreduction in the CACA guidelines [10]; however, since all patients in the present study were retrospectively reviewed, we cannot reasonably explain how patients were selected to receive cytoreduction plus HIPEC rather than cytoreduction alone. Another limitation is that not all patients received the same comprehensive treatment model, and the followup period was short. Therefore, although the recurrence-free survival of our cohort is comparable to that in previous studies, the median OS was not achieved. Additionally, the sample size of the present study was relatively small, and the potential influence from the type of HIPEC device cannot be excluded.

\section{Conclusions}

For ovarian cancer patients who receive cisplatin for HIPEC at $43{ }^{\circ} \mathrm{C}$, the AD of cisplatin can be calculated from the $\mathrm{TD}$ and $\mathrm{VP}_{\text {retained }}$ using the following equation: $\mathrm{AD}(\mathrm{mg})=30.079+0.667 \mathrm{TD}(\mathrm{mg})-0.010 \mathrm{VP}_{\text {retained }}$ $(\mathrm{ml})$. AD has no prognostic influence. Our work could help guide dose planning for cisplatin when HIPEC is indicated. Larger prospective trials are needed to validate our findings.

\section{Supplementary Information}

The online version contains supplementary material available at https://doi. org/10.1186/s13048-021-00764-6.

Additional file 1. Adverse events

\section{Abbreviations}

AD: Actually utilized dose; AKl: Acute kidney injury; AE: Adverse event; BMI: Body mass index; Cl: Confidence interval; HR: Hazard ratio; HIPE 
C: Hyperthermic intraperitoneal chemotherapy; ICP-MS: Inductively coupled plasma mass spectrometry; IDS: Interval debulking surgery; IPC: Intraperitoneal chemotherapy; LD: Losing dose; NCCN: National Comprehensive Cancer Network; NACT: Neoadjuvant chemotherapy; OS: Overall survival; PDS: Primary debulking surgery; PFS: Recurrence-free survival; CACA: The China Anti-Cancer Association; NCI-CTCAE: The National Cancer Institute Common Terminology Criteria for Adverse Events; TD: Total dose; Vpretained: Volume of the perfusate that was retained

\section{Acknowledgments}

We would like to acknowledge all the research coordinators at the Department of Gynecologic Oncology at Sun Yat-sen Memorial Hospital. We are deeply grateful to the patients who provided samples for this study and all clinicians who referred cases.

\section{Authors' contributions}

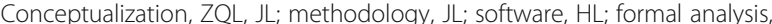
WYW; data curation, WYW, HL; writing-original draft preparation, WYW, JL; writing-review and editing, JL, ZQL; supervision, ZQL, JL; project administration, WYW, MFW, DBW, LWW; funding acquisition, JL. All authors have read and agreed to the published version of the manuscript.

\section{Funding}

This research was funded by China Scholarship Council, grant number 201906385061

\section{Availability of data and materials}

The datasets generated during and analyzed during the current study are available from the corresponding author on reasonable request.

\section{Ethics approval and consent to participate}

This study was approved by the Institutional Review Board of the Sun Yatsen Memorial Hospital (Approval No. SYSEC-KY-KS-2020-046) in accordance with the Declaration of Helsinki and the International Conference on Harmonization Good Clinical Practice guidelines.

\section{Consent for publication}

The publication has been approved by all co-authors.

\section{Competing interests}

None of the authors declared any conflict of interest regarding the subject of the study.

\section{Author details}

'Department of Gynecologic Oncology, Sun Yat-sen Memorial Hospital, Sun Yat-sen University, Guangzhou 510120, People's Republic of China. ${ }^{2}$ Department of Obstetrics and Gynecology, Kiang Wu Hospital, 85-87 R. de Coelho do Amaral, Macau 96000, People's Republic of China.

\section{Received: 30 November 2020 Accepted: 1 January 2021}

\section{Published online: 08 January 2021}

\section{References}

1. Siegel RL, Miller KD, Jemal A. Cancer statistics, 2020. CA Cancer J Clin. 2020; 70:7-30. https://doi.org/10.3322/caac.21590.

2. Ledermann JA, Raja FA, Fotopoulou C, Gonzalez-Martin A, Colombo N, Sessa $C$, et al. Newly diagnosed and relapsed epithelial ovarian carcinoma: ESMO clinical practice guidelines for diagnosis, treatment and follow-up. Ann Oncol. 2018:29:iv259. https://doi.org/10.1093/annonc/mdy157.

3. Armstrong DK, Bundy B, Wenzel L, Huang HQ, Baergen R, Lele S, et al. Intraperitoneal cisplatin and paclitaxel in ovarian cancer. N Engl J Med. 2006;354:34-43. https://doi.org/10.1056/NEJMoa052985.

4. van Driel WJ, Koole SN, Sikorska K. Schagen van Leeuwen JH, Schreuder HWR, Hermans RHM, et al. Hyperthermic Intraperitoneal chemotherapy in ovarian cancer. N Engl J Med. 2018;378:230-40. https://doi.org/10.1056/ NEJMoa1708618.

5. Petrillo M, De laco P, Cianci S, Perrone M, Costantini B, Ronsini C, et al. Long-term survival for platinum-sensitive recurrent ovarian cancer patients treated with secondary Cytoreductive surgery plus Hyperthermic Intraperitoneal chemotherapy (HIPEC). Ann Surg Oncol. 2016:23:1660-5. https://doi.org/10.1245/s10434-015-5050-x.
6. Zhang G, Zhu Y, Liu C, Chao G, Cui R, Zhang Z. The prognosis impact of hyperthermic intraperitoneal chemotherapy (HIPEC) plus cytoreductive surgery (CRS) in advanced ovarian cancer: the meta-analysis. J Ovarian Res. 2019:12:33. https://doi.org/10.1186/s13048-019-0509-1.

7. Spiliotis J, Halkia E, Lianos E, Kalantzi N, Grivas A, Efstathiou E, et al. Cytoreductive surgery and HIPEC in recurrent epithelial ovarian cancer: a prospective randomized phase III study. Ann Surg Oncol. 2015;22:1570-5. https://doi.org/10.1245/s10434-014-4157-9.

8. Lei Z, Wang Y, Wang J, Wang K, Tian J, Zhao Y, et al. Evaluation of Cytoreductive surgery with or without Hyperthermic Intraperitoneal chemotherapy for stage III epithelial ovarian cancer. JAMA Netw Open. 2020;3:e2013940. https://doi.org/10.1001/jamanetworkopen.2020.13940.

9. Armstrong DK, Alvarez RD, Bakkum-Gamez JN, Barroilhet L, Behbakht K, Berchuck A, et al. NCCN guidelines insights: ovarian cancer, version 1.2019. J Natl Compr Cancer Netw. 2019;17:896-909. https://doi.org/10.6004/jncen. 2019.0039.

10. Li Y, Zhou YF, Liang H, Wang HQ, Hao JH, Zhu ZG, et al. Chinese expert consensus on cytoreductive surgery and hyperthermic intraperitoneal chemotherapy for peritoneal malignancies. World J Gastroenterol. 2016;22: 6906-16. https://doi.org/10.3748/wjg.v22.i30.6906.

11. Aabo K, Adams M, Adnitt P, Alberts DS, Athanazziou A, Barley V, et al. Chemotherapy in advanced ovarian cancer: four systematic meta-analyses of individual patient data from 37 randomized trials. Advanced ovarian cancer Trialists' group. Br J Cancer. 1998;78:1479-87. https://doi.org/10.1038/ bjc.1998.710.

12. Gonzalez-Moreno S, Gonzalez-Bayon LA, Ortega-Perez G. Hyperthermic intraperitoneal chemotherapy: rationale and technique. World J Gastrointest Oncol. 2010;2:68-75. https://doi.org/10.4251/wjgo.v2.i2.68.

13. Lemoine L, Sugarbaker P, Van der Speeten K. Drugs, doses, and durations of intraperitoneal chemotherapy: standardising HIPEC and EPIC for colorectal, appendiceal, gastric, ovarian peritoneal surface malignancies and peritoneal mesothelioma. Int J Hyperth. 2017;33:582-92. https://doi.org/10.1080/ 02656736.2017.1291999.

14. Cashin PH, Ehrsson H, Wallin I, Nygren P, Mahteme H. Pharmacokinetics of cisplatin during hyperthermic intraperitoneal treatment of peritoneal carcinomatosis. Eur J Clin Pharmacol. 2013;69:533-40. https://doi.org/10. 1007/s00228-012-1405-4

15. Ansaloni L, Coccolini F, Morosi L, Ballerini A, Ceresoli M, Grosso G, et al. Pharmacokinetics of concomitant cisplatin and paclitaxel administered by hyperthermic intraperitoneal chemotherapy to patients with peritoneal carcinomatosis from epithelial ovarian cancer. Br J Cancer. 2015;112:306-12. https://doi.org/10.1038/bjc.2014.602.

16. Kern W, Braess J, Kotschofsky M, Samel S, Becker H, Hiddemann W, et al. Application of cisplatin as intraoperative hyperthermic peritoneal lavage (IHPL) in patients with locally advanced gastric cancer: analysis of pharmacokinetics and of nephrotoxicity. Anticancer Res. 2002;22:3099-102.

17. Winter WE 3rd, Maxwell GL, Tian C, Sundborg MJ, Rose GS, Rose PG, et al. Tumor residual after surgical cytoreduction in prediction of clinical outcome in stage IV epithelial ovarian cancer: a gynecologic oncology group study. J Clin Oncol. 2008;26:83-9. https://doi.org/10.1200/JCO.2007.13.1953.

18. Pavlov MJ, Ceranic MS, Latincic SM, Sabljak PV, Kecmanovic DM, Sugarbaker $\mathrm{PH}$. Cytoreductive surgery and hyperthermic intraperitoneal chemotherapy for the treatment of advanced epithelial and recurrent ovarian carcinoma: a single center experience. Int J Hyperth. 2018;34:564-9. https://doi.org/10. 1080/02656736.2017.1371341.

19. Somashekhar SP, Yethadka R, Kumar CR, Ashwin KR, Zaveri S, Rauthan A. Toxicity profile of chemotherapy agents used in cytoreductive surgery and hyperthermic intraperitoneal chemotherapy for peritoneal surface malignancies. Eur J Surg Oncol. 2020;46:577-81. https://doi.org/10.1016/j. ejso.2019.10.032

20. Van der Speeten K, Stuart OA, Mahteme H, Sugarbaker PH. Pharmacokinetic study of perioperative intravenous Ifosfamide. Int I Surg Oncol. 2011;2011: 185092. https://doi.org/10.1155/2011/185092.

21. Deraco M, Baratti D, Cabras AD, Zaffaroni N, Perrone F, Villa R, et al. Experience with peritoneal mesothelioma at the Milan National Cancer Institute. World J Gastrointest Oncol. 2010;2:76-84. https://doi.org/10.4251/ wjgo.v2.i2.76.

22. Oh GS, Kim HJ, Shen A, Lee SB, Khadka D, Pandit A, et al. Cisplatininduced kidney dysfunction and perspectives on improving treatment strategies. Electrolyte Blood Press. 2014;12:55-65. https://doi.org/10.5049/ EBP 2014.12.255. 
23. Gouy S, Ferron G, Glehen O, Bayar A, Marchal F, Pomel C, et al. Results of a multicenter phase I dose-finding trial of hyperthermic intraperitoneal cisplatin after neoadjuvant chemotherapy and complete cytoreductive surgery and followed by maintenance bevacizumab in initially unresectable ovarian cancer. Gynecol Oncol. 2016;142:237-42. https:/doi.org/10.1016/j. ygyno.2016.05.032

24. Verwaal VJ, van Ruth $\mathrm{S}$, de Bree E, van Sloothen GW, van Tinteren $\mathrm{H}$, Boot $\mathrm{H}$, et al. Randomized trial of cytoreduction and hyperthermic intraperitoneal chemotherapy versus systemic chemotherapy and palliative surgery in patients with peritoneal carcinomatosis of colorectal cancer. J Clin Oncol. 2003:21:3737-43. https://doi.org/10.1200/JCO.2003.04.187.

25. Kusamura S, Baratti D, Younan R, Laterza B, Oliva GD, Costanzo P, et al. Impact of cytoreductive surgery and hyperthermic intraperitoneal chemotherapy on systemic toxicity. Ann Surg Oncol. 2007;14:2550-8. https://doi.org/10.1245/s10434-007-9429-1.

26. Canda AE, Sokmen S, Terzi C, Arslan C, Oztop I, Karabulut B, et al. Complications and toxicities after cytoreductive surgery and hyperthermic intraperitoneal chemotherapy. Ann Surg Oncol. 2013;20:1082-7. https://doi. org/10.1245/s10434-012-2853-x.

27. Cata JP, Zavala AM, Van Meter A, Williams UU, Soliz J, Hernandez M, et al. Identification of risk factors associated with postoperative acute kidney injury after cytoreductive surgery with hyperthermic intraperitoneal chemotherapy: a retrospective study. Int J Hyperth. 2018;34:538-44. https:// doi.org/10.1080/02656736.2017.1368096.

28. Khrunin A, Ivanova F, Moisseev A, Khokhrin D, Sleptsova Y, Gorbunova V, et al. Pharmacogenomics of cisplatin-based chemotherapy in ovarian cancer patients of different ethnic origins. Pharmacogenomics. 2012;13:171-8. https://doi.org/10.2217/pgs.11.140.

29. Sin El, Chia CS, Tan GHC, Soo KC, Teo MC. Acute kidney injury in ovarian cancer patients undergoing cytoreductive surgery and hyperthermic intraperitoneal chemotherapy. Int J Hyperth. 2017;33:690-5. https://doi.org/10. 1080/02656736.2017.1293304.

30. Laplace N, Kepenekian V, Friggeri A, Vassal O, Ranchon F, Rioufol C, et al. Sodium thiosulfate protects from renal impairement following hyperthermic intraperitoneal chemotherapy (HIPEC) with Cisplatin. Int J Hyperth. 2020;37: 897-902. https://doi.org/10.1080/02656736.2020.1795277.

31. Ba M, Long H, Zhang X, Tang Y, Wu Y, Wang S, et al. Hyperthermic Intraperitoneal perfusion chemotherapy and Cytoreductive surgery for controlling malignant ascites from ovarian cancer. Int J Gynecol Cancer. 2016;26:1571-9. https://doi.org/10.1097/IGC.0000000000000809.

32. Ba MC, Long H, Cui SZ, Tang YQ, Wu YB, Zhang XL, et al. Multivariate comparison of B-ultrasound guided and laparoscopic continuous circulatory hyperthermic intraperitoneal perfusion chemotherapy for malignant ascites. Surg Endosc. 2013;27:2735-43. https://doi.org/10.1007/s00464-013-2800-3.

33. Gao T, Huang XX, Wang WY, Wu MF, Lin ZQ, Li J. Feasibility and safety of neoadjuvant laparoscopic hyperthermic intraperitoneal chemotherapy in patients with advanced stage ovarian cancer: a single-center experience. Cancer Manag Res. 2019:11:6931-40. https://doi.org/10.2147/CMAR.S213882.

34. Li XB, Ma R, Ji ZH, Lin YL, Zhang J, Yang ZR, et al. Perioperative safety after cytoreductive surgery plus hyperthermic intraperitoneal chemotherapy for pseudomyxoma peritonei from appendiceal origin: experience on 254 patients from a single center. Eur J Surg Oncol. 2020;46:600. https://doi.org/ 10.1016/j.ejso.2020.01.017.

35. Rossmanna C, Haemmerich D. Review of temperature dependence of thermal properties, dielectric properties, and perfusion of biological tissues at hyperthermic and ablation temperatures. Crit Rev Biomed Eng. 2014;42: 467-92. https://doi.org/10.1615/critrevbiomedeng.2015012486.

\section{Publisher's Note}

Springer Nature remains neutral with regard to jurisdictional claims in published maps and institutional affiliations.

Ready to submit your research? Choose BMC and benefit from:

- fast, convenient online submission

- thorough peer review by experienced researchers in your field

- rapid publication on acceptance

- support for research data, including large and complex data types

- gold Open Access which fosters wider collaboration and increased citations

- maximum visibility for your research: over $100 \mathrm{M}$ website views per year

At BMC, research is always in progress.

Learn more biomedcentral.com/submissions 